\title{
PRÁCTICAS URBANAS ENTRE LA REGULARIZACIÓN Y EL MERCADO INFORMAL DE VIVIENDA El caso de la Villa 31 en Buenos Aires
}

\author{
Autor: Ph.D Dipl- Ing. Sophie Naue \\ Universidad Piloto de Colombia \\ E-Mail: naue.sophie1@gmail.com
}

\section{RESUMEN}

La Villa 31 es uno de los barrios informales más antiguos de Buenos Aires. Desde hace varias décadas su ubicación en el centro de la ciudad ha generado un discurso público muy diverso. Pero no solo el valor y uso de las tierras provocan diferentes intereses económicos y políticos, sino también es consecuencia de una demanda habitacional que origina una economía interna, entre los habitantes del barrio. Partiendo del caso de estudio el siguiente artículo se centra en dos sucesos actuales: Por un lado, se analiza la implementación y el avance del proceso de regularización (mejoramiento) del barrio, por el otro lado, la investigación se focaliza en el desarrollo de un mercado de vivienda propio dentro de la Villa 31. En el foco de interés están las prácticas de apropiación espacial y la transformación del acceso a la vivienda por el funcionamiento del mercado informal de vivienda.

Palabras clave: Informalidad, Proceso de Regularización, Mercado de Vivienda Informal, Practicas Urbanas

\begin{abstract}
The present article deals with the Villa 31, one of the oldest informal settlement in Buenos Aires. For decades its location in the city center has generated a very diverse public discourse. But not only its value and use of land provoke different economic and political interests, they are also a consequence of a housing demand that originates an internal economy among the inhabitants of the neighbourhood. Based on the urban context of this specific place, the article concentrates on two present developments: On the one hand the process of reassessment (and upgrading) of the Villa 31 is examined, which has been initiated and established by the city administration. On the other hand the analysis focuses on the development of a parallel functioning informal housing market within the settlement. In the centre of interest are the practices of appropriation of housing (habitat) and their transformation by the rules of an informal market.
\end{abstract}

Key words: Informality, Upgrading Process, Informal Housing Market, Urban Practice 


\section{MOTIVO DE LA INVESTIGACIÓN Y PLANTEAMIENTO}

Hay territorios que se encuentran fuera de un orden común, aunque se localizan en la ciudad, Foucault llama estos espacios Heterotopien. Ubicada en pleno centro de la ciudad de Buenos Aires, pero no registrada en ningún mapa, la Villa 31 es uno de esos lugares, aparentemente invisibles y al mismo tiempo en el foco de un discurso político y público.

El punto de partida de la investigación se enmarca en la legislación de la Ley $\mathrm{N}^{\circ} 3.343$ que decreta la radicación y urbanización ${ }^{1}$ de la Villa 31 , tal ley fue discutida durante décadas y finalmente aprobada en diciembre del año 2009. Sin embargo, en los últimos años no sólo se implementó un proceso de regularización y mejoramiento barrial a través de dicha ley, sino también la demanda habitacional y la falta de tierras accesibles impulsaron el desarrollo de un propio mercado de vivienda dentro del barrio. A continuación, el artículo tiene como propósito analizar el proceso de regularización y poner en evidencia las dinámicas y los cambios generados por el mercado informal. Bajo estas circunstancias se considera, que el funcionamiento de dicho mercado marca uno de los desafíos esenciales en relación al futuro desarrollo de la Villa 31 y se plantea: ¿Qué influencia tienen los procesos de transformación socio espacial por medio de la "regularización" y el desarrollo del mercado informal de viviendas en el espacio urbano y en la vida cotidiana de los habitantes en la Villa 31?

El artículo se concentra en un análisis crítico de dicho desarrollo y transformación, que hasta el momento no ha sido considerado científicamente. Debido a que el conocimiento de las condiciones locales exige una comprensión profunda de las dinámicas específicas del lugar, en el marco de un análisis etnográfico urbano, la investigación de campo se concentra en las diferentes perspectivas, experiencias, prácticas urbanas y negociaciones de los habitantes del barrio. La triangulación de distintos métodos: observaciones participativas, mapeos, entrevistas cualitativas y la evaluación de las entrevistas relacionadas a la grounded theory, permiten un amplio conocimiento del barrio, su contexto urbano y de las dinámicas del mercado informal de vivienda. En base a este análisis, se muestran los conflictos, como también los retos asociados con el programa de mejoras y el desarrollo del mercado informal de vivienda.
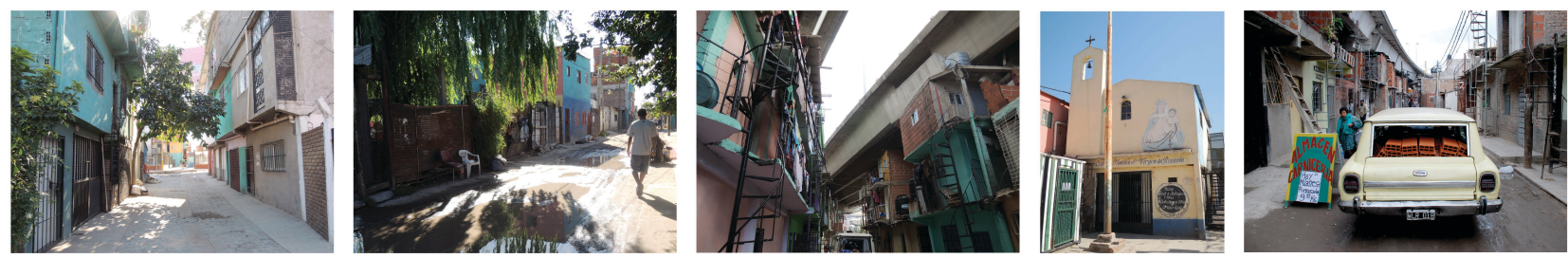

Figura 1. Impresiones Villa 31, propias imágenes fotográficas (2014)

\section{CONTEXTO (URBANO / HISTÓRICO) VILLA 31}

La Villa 31 es uno de los asentamientos históricos de Buenos Aires. El barrio se formó en los años 1930 como una ocupación de trabajadores inmigrantes (en su mayoría de Italia y Polonia), que se instalaron en la zona de Retiro, por las distintas oportunidades de trabajo que habían en el puerto o ferroviario (cf. Thimmel 2004: 184). A causa de la crisis rural en Argentina, la Villa 31 empezó a crecer durante esta época, debido a que la población de zonas rurales inmigró del campo a los centros urbanos del país, buscando mejorar sus condiciones de vida y trabajo. Desde entonces el continuo crecimiento del barrio está marcado por la migración interna del país (rural-urbana), como también a partir de los años 1960 de los países limítrofes (cf. Carvino 2006: 81 - 83). Mientras que en décadas posteriores, durante la dictadura militar (1976 -1983), las demás "Villas Miserias" fueron en su mayoría erradicadas de la Capital Federal ${ }^{2}$ y sus habitantes re localizados al sur de la ciudad, la provincia la Villa 31 permaneció en el centro de la ciudad (cf. Carvino 2006: $86){ }^{3}$

\footnotetext{
${ }^{1}$ El termino urbanización en Argentina se utiliza entre otros, para describir procesos institucionales de mejoras en las Villas Miserias (regularización y formalización).

2 Debido a la política de erradicación de Villas de Emergencia que se inició en 1977, se erradicaron diecisiete Villas y se redujo la población 84 \% (Censo Nacional de Población, Hogares y Viviendas 2010 en la Ciudad de Buenos Aires).

${ }^{3}$ Aunque la mayoría de los habitantes de la Villa 31 también fueron desalojados, el barrio nunca fue erradicado por completo y se volvió a poblar después de la caída del régimen militar.
} 


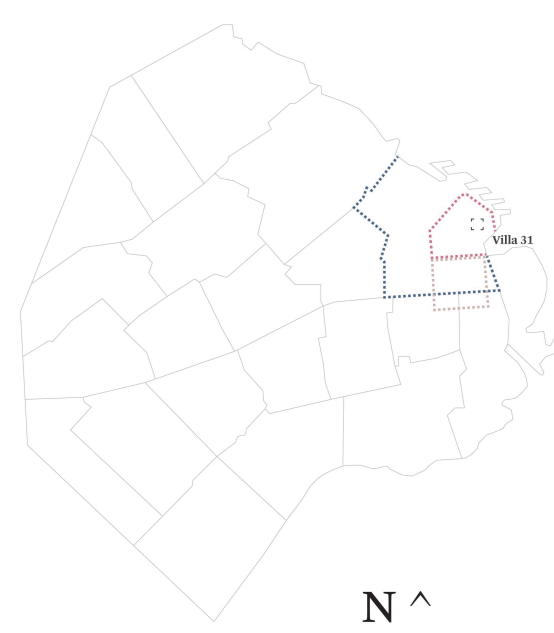

$\mathrm{N}^{\wedge}$

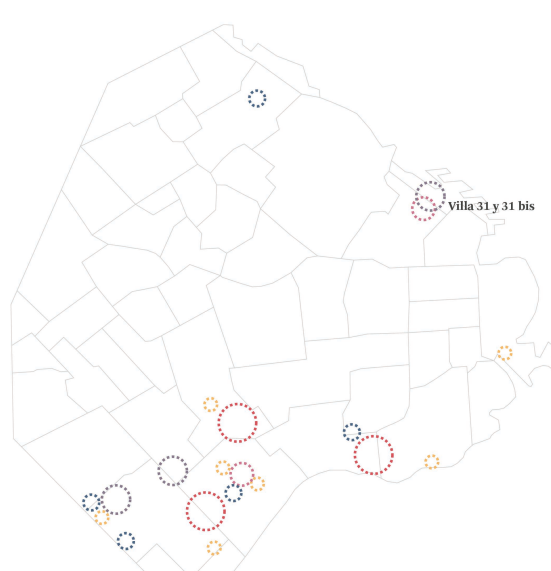

$\mathrm{N}^{\wedge}$

Figura 1. Ubicación de la Villa 31 / Figura 2. Ubicación de las Villas Miserias en Buenos Aires

Elaboración propia a partir de mapa.buenosaires.gov.ar (2009), Diagnóstico de la emergencia habitacional en la ciudad de Buenos Aires.

Por causa de su historia y ubicación (en el centro de la ciudad), la Villa 31 es un lugar emblemático y a la vez estratégico; Por un lado, causa intereses económicos muy fuertes debido al valor de sus tierras, los intereses de emprendedores privados y las diferentes intenciones políticas. ${ }^{4}$ Por el otro lado su localización y la centralidad permiten a sus habitantes un mejor acceso a la "ciudad", con su campo de trabajo, su infraestructura y los equipamientos públicos. El entorno urbano de la villa se caracteriza por una gran variedad de zonas de alta frecuencia, pero también por lugares exclusivos.

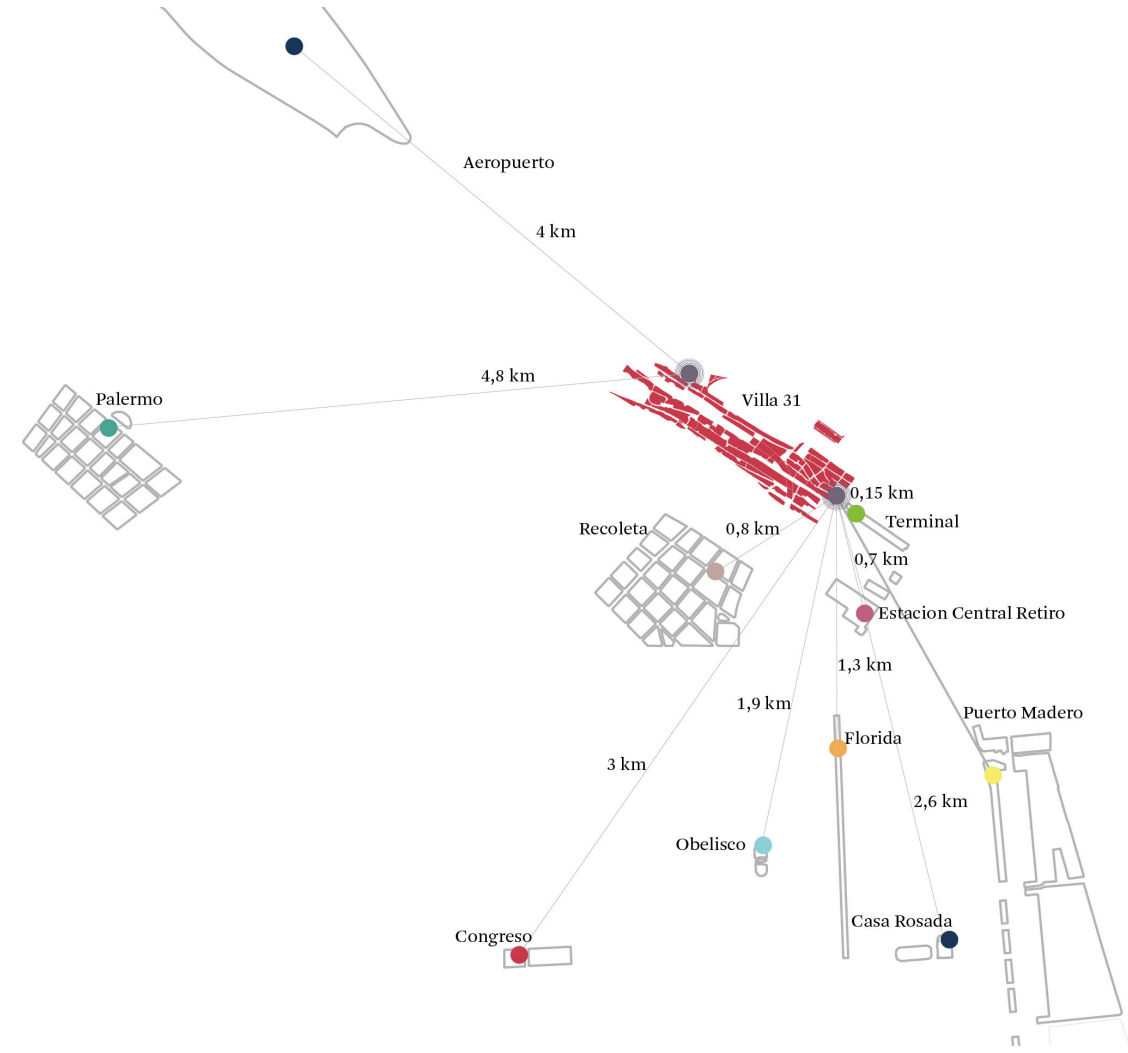

Figura 3. Contexto urbano de la Villa 31

\footnotetext{
${ }^{4}$ Según Salerno "Un elemento que introduce complejidad a las discusiones sobre esta villa se asocia al complejo panorama institucional que presenta. En este sentido, si bien la villa de Retiro se asienta dentro de la jurisdicción de la ciudad Autónoma de Buenos Aires, la propiedad de las tierras es en su mayor parte del Estado Nacional" (Salerno 2014: 30).
} 
Según el último censo 2009 la Villa 31 tiene una población de 27.960 personas (Censo de Hogares y Población Villa 31 y 31 Bis. Ciudad de Buenos Aires). Sin embargo, las cifras no oficiales son mucho más altas e indican una población de aproximadamente 45.000 mil personas. Su continuo crecimiento esta marcado por la migración interna del país (rural-urbana), como también de los países limítrofes.

El tejido urbano del barrio representa la suma de prácticas individuales por un tiempo indeterminado, es disperso, denso y además no toma en cuenta las reglas morfológicas de la ciudad formal. Por lo tanto, el barrio se contrasta con su entorno urbano, que cuenta con una trama ortogonal y bloques consolidados.

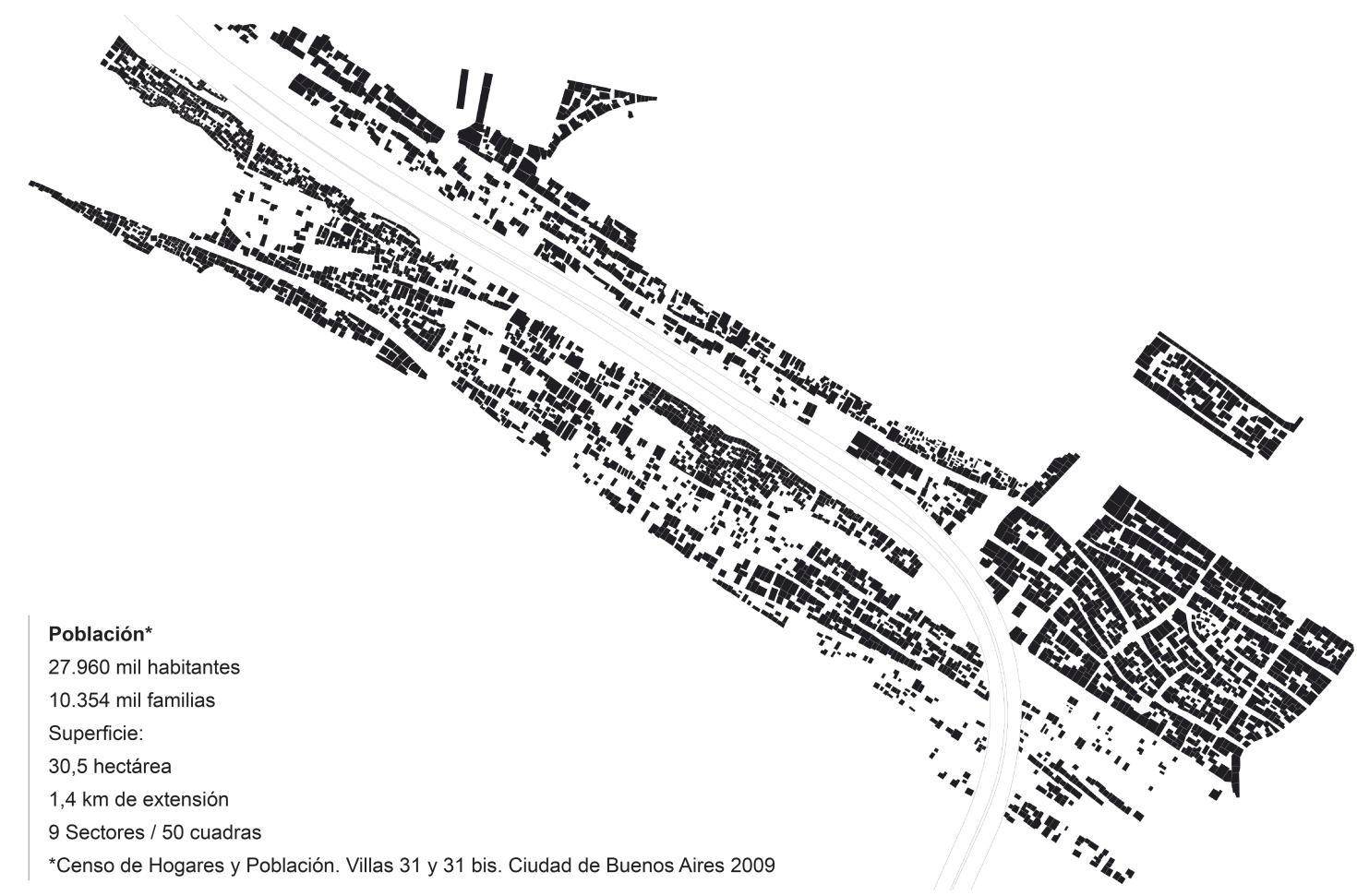

Figura 5. Estructura morfológica de la Villa 31

Elaboración propia a partir de fotografía aérea del Gobierno de la Ciudad Autónoma de Buenos Aires, Ministerio de Desarrollo (2012).

Aunque la Villa 31 fue tolerada por parte de las autoridades públicas, el barrio continúo por décadas con el estatus de la informalidad. ${ }^{5}$ A diferencia de las otras Villas Miseria, el barrio (hasta el año 2010) no fue integrado en algún programa de mejora o regularización ${ }^{6}$ y sus habitantes corrieron el riesgo permanente de ser desalojados. Con el paso del tiempo se consolidaron las estructuras urbanas y socio espaciales, ${ }^{7}$ pero los habitantes en su mayoría siguen viviendo en circunstancias precarias y sin seguridad o garantía de la tenencia.

\section{PRACTICAS DE REGULARIZACIÓN}

La falta de decisiones políticas y su incumplimiento por parte del gobierno marcan la larga historia de la Villa 31 . En este contexto la legislación de la ley $N^{\circ} 3.343$ (que decreta la urbanización y radicación definitiva de la Villa 31 y de aquellas personas que habitan el polígono que comprende a este área 12/2009), define un

\footnotetext{
5 “[...) fue la única de las grandes Villas de la ciudad que surgió presentando un estado de indefinición en relación a su futuro" (cf. Salerno, 2014: 134).

${ }^{6}$ La ubicación y los diferentes intereses económicos que causa el valor de las tierras son los aspectos más importantes, por los cuales la Villa 31, por muchos años no ha sido integrada en algún programa de integración o mejora por parte del estado, aunque el barrio forma parte de las "villas tradicionales".

${ }^{7}$ Con el tiempo las construcciones espontáneas se reemplazaron por casas de ladrillo, se mejoró la infraestructura, se estabilizaron las redes sociales y la organización dentro de la comunidad.
} 
cambio paradigmático, entre una política de erradicación y hacia la radicación e integración de la Villa 31. Desde entonces en el año 2010 se condonó por decreto el "Programa de Mejoras para las Villas 31 y 31 bis" (Decreto 495 / 2010). Respecto al tema el arquitecto Javier Fernández Castro (quien jugó un papel importante en la elaboración de un concepto de urbanización alternativo), dice:

"La erradicación de la Villa 31 ya no es negociable [...]. La villa tiene un valor histórico, este lugar es el hogar de más de 30.000 personas. Políticamente la demolición de la Villa ya no es factible, porque Argentina ya no se encuentra en una dictadura. Ganamos las discusiones sobre la radicación y la eventual demolición del asentamiento. Hasta los macristas ${ }^{8}$ están al favor de la urbanización, aunque no hacen mucho para ponerlo en práctica” (Entrevista: Fernández Castro, 2014).

\subsection{Programa de Mejoras}

Con el inicio del Programa de Mejoras, se propone mejorar la situación inmediata de la Villa 31 hasta poder contar con el proyecto de urbanización definitivo (cf. Hidalgo; Janoschka, 2014: 144). En su marco se ejecutaron diferentes intervenciones y proyectos tanto en las fachadas, como también en el espacio público, el equipamiento y la infraestructura técnica, las cuales representaron mejoras en varios aspectos para el barrio y sus habitantes. Una de las primeras intervenciones fue pintar las fachadas de las casas de diferentes colores (con el objetivo de cambiar la imagen del barrio). Durante un año se pintaron más de 100.000 metros cuadrados (cf. Salerno 2014: 145). Una intervención que tiene una alta visibilidad, se pudo realizar a corto plazo y sin mayores costos. Sin embargo, se trata de una práctica pintoresca, que no tiene influencia en las condiciones de vida dentro del barrio.

"En los últimos años empezaron con diferentes obras, asfaltaron las calles, pintaron las casas y mejoraron las cloacas, así la calidad de vida sí se ha mejorado. Pero siempre vamos a ser la Villa 31, allí pueden pintar tantas casas que quieren "(Interview: Alejandra García, 2013 / Dueña del Salón Comunal Arca de Noé, sector YPF Villa 31).

El mayor impacto que tuvo el Programa de Mejoras en el entorno urbano del barrio fue por la recuperación y revalorización del espacio público. En total se mejoraron y diseñaron nuevamente 18 plazas y canchas deportivas. Un hecho relevante, considerando que el espacio público en la Villa 31 tiene una importancia en particular, ya que en la mayoría de las viviendas las características y condiciones espaciales son muy limitadas o reducidas.

"Lo que están haciendo es una pre urbanización. Están abriendo las calles, arreglando los espacios públicos y todas estas cosas. Yo estoy de acuerdo y me parece muy bien. La Villa es bonita, pero ahora la volvemos hacer más bonita. Un proyecto de estos no se deja realizar en una noche." (Entrevista: Luís Baza, 2013 / Residente de la Villa hace más de 73 años, sector Güemes Villa 31
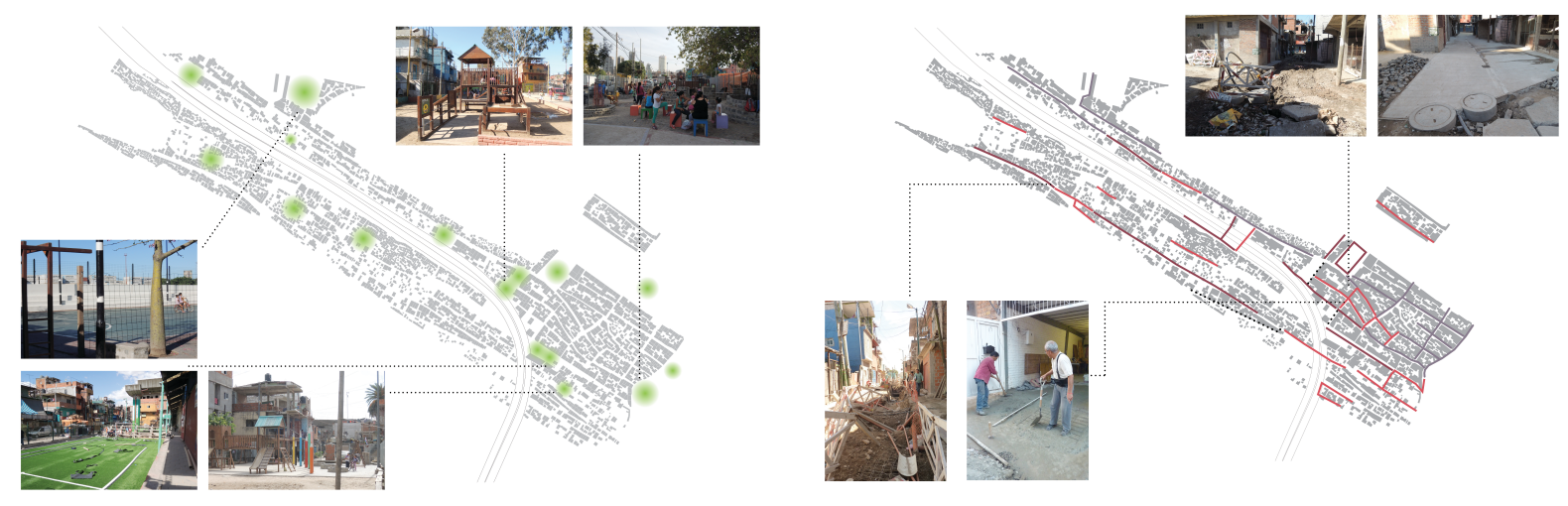

Figura 6: Mapa con las mejoras en el espacio público / Figura 7: Mapa con las obras de mejora de la infraestructura técnica Elaboración propia a partir de investigación de campo (2014), propias imágenes fotográficas (2015).

\footnotetext{
${ }^{8}$ Partidarios del actual presidente argentino Mauricio Macri.
} 
Respecto al desarrollo de las obras de infraestructura técnica, se realizaron aproximadamente 3.100 metros de redes pluviales, cloacales y de agua potable, además se asfaltaron alrededor de 3.000 metros de calles (cf. Salerno 2014: 145). Las obras de infraestructura son indispensables para mejorar las condiciones de vida dentro del barrio, pero a la vez fueron criticadas por el lento avance y su calidad.

Por parte de los habitantes el proceso de mejora no sólo está vinculado con esperanza y expectativas, sino también con diferentes preocupaciones y temores. En este contexto y con el fin de mantener el carácter propio del lugar, se deben reconocer y preservar las redes sociales como también las estrategias de auto gestión, ya que estas funcionan de manera flexible (apropiados a la necesidad) y compensan la falta de estructuras estatales. También es necesario preservar el tejido urbano propio del barrio, el cuál se fue consolidando con el tiempo. Con las estructuras urbanas no sólo se hace referencia al valor espacial, sino también al valor social que se expresa en la identidad de los habitantes con su entorno construido.

"Nosotros pedimos que con el proceso de urbanización, reconozcan lo que la gente del barrio fue construyendo por décadas. Tienen que respetar la forma como vive la gente del barrio. [...] En el proyecto que nosotros armamos con el arquitecto Javier Fernández Castro el 70 \% de la Villa se queda como está. Nosotros defendemos la identidad, cultural y la disposición territorial que ha sido construido por la misma gente. Obviamente hay que mejorar la situación y mejorar los servicios públicos, pero rescatamos lo que la gente hizo" (Entrevista: Julián Wald, 2013 / Líder Comunal, sector Comunicaciones, Villa 31).

Además de conectar el barrio a la red de servicios públicos, los habitantes entienden, bajo el término de "urbanización", también el derecho de residencia mediante la concesión de sus títulos de propiedad, sin embargo, en este contexto, no se han realizado avances.

"Yo tengo el miedo, que con los planes de mejoras sólo quieren calmar la población. De primer vista, las intenciones del gobierno parecen bien, pero en realidad todo es muy superficial y no tienen trasfondo. Todos deben estar agradecidos por las nuevas plazas, los juegos y no decir que realmente quieren que les transfieren los títulos de propiedad" (Entrevista: Reed, 2013 / Habitante del sector Güemes Villa 31).

\subsection{Crítica de las prácticas de regularización}

En general hay que reconocer la importancia que tienen los proyectos realizados para el barrio, sus habitantes y la puesta en valor del hábitat, no obstante, los resultados de manera consecutiva son casi siempre cuestionables. En el caso de la Villa 31, el análisis demuestra que las intervenciones no son de carácter sustentable. En vez de establecer un programa integral a largo plazo, se realizaron (excepto de las obras de infraestructura), únicamente intervenciones puntuales. En referencia a la antropóloga argentina María Cristina Cravino, la política hacia las Villas desarrolladas por el gobierno del $\mathrm{PRO}^{9}$, persigue un paradigma, que ella nombra "maquillaje urbano". Es decir, "la intervención en el espacio público o en las fachadas de las viviendas, sin que se modifiquen las condiciones estructurales de los barrios. Detrás de esta idea puede encontrarse la intención de intervenciones cortas en el tiempo y de baja inversión pública, pero de alto impacto en el marketing urbano - tanto interno como externo" (Cravino 2013).

La implementación de dicho paradigma se puede observar evidentemente en el caso de la Villa 31. Aunque se estabilizó el Programa de Mejoras para la Villa 31 y 31 bis, ninguno de los proyectos ha logrado mejoras relevantes en las condiciones habitacionales o en la seguridad de la tenencia, que continua sin ser resuelta. ${ }^{10}$ Hasta el momento el gobierno no tuvo la voluntad para establecer estrategias de formalización en la Villa 31, transfiriendo, por ejemplo los títulos de propiedad a sus habitantes. De manera consecuente a las decisiones gubernamentales tomadas, se puede observar que se ha generado un "nuevo fenómeno" que introduce una complejidad a la temática (de garantizar a los habitantes la seguridad de la tenencia de sus viviendas), lo cuál es el desarrollo y la consolidación de un "mercado informal de vivienda" en la Villa 31.

\footnotetext{
9 Propuesta Republicana (PRO) es un partido político argentino reconocido legalmente en 2005.

${ }^{10}$ Teniendo en cuanta a Edésio Fernández "Las políticas de regularización tienen que tener un fundamento más coherente que resuelva la seguridad de la tenencia, los derechos legales de los dueños de la propiedad y el suministro de infraestructura urbana y servicios" (Fernández 2011: 21).
} 


\section{EL MERCADO DE VIVIENDA DE LA VILLA 31}

En los últimos años, la demanda habitacional no resuelta por parte del estado, debido al limitado alcance de las políticas públicas de suelo, la falta de tierras y de vivienda de interés social, impulsaron el desarrollo de un mercado de vivienda propio ${ }^{11}$ en la Villa 31. En consecuencia, se plantea que existe un conflicto entre la titulación (en el marco legal de la urbanización) y el funcionamiento de dicho mercado. Dado a lo anterior el mercado informal de vivienda marca uno de los desafíos esenciales en relación al futuro desarrollo de la Villa 31.

"Existe un mercado en donde puedes subalquilar una habitación, vender tu casa y incluso vender un terreno, aunque el suelo de tu casa, en realidad no te pertenece. Si vendes tu casa, realmente sólo vendes el material, nada más. Aquí en la villa no hay ningún habitante que es dueño de la tierra, no importa si la persona te dice que compró la casa o la tierra misma, y por lo tanto es el dueño. Aquí nadie tiene un título de propiedad. Nadie es el dueño reconocido legalmente" (Entrevista: Verónica Azua, 2014 / Inquilina Güemes Villa 31).

Dicho funcionamiento del mercado informal de vivienda hasta el momento no solo, no se ha considerado y analizado científicamente, sino también se encuentra fuera del control estatal. ${ }^{12}$ En este contexto, el artículo tiene como objetivo analizar el funcionamiento y los mecanismos pocos conocidos del mercado informal. A través de entrevistas con los actores principales (dueños, inquilinos, vendedores y compradores de casas y terrenos), se observaron las prácticas de apropiación del suelo y la transformación del acceso a la vivienda, como también las diferentes motivaciones, proyecciones y conflictos. Además, se analizó el impacto que tuvo la densificación a la forma tradicional de construcción, la transformación de las tipologías, las nuevas circunstancias económicas, las formas de seguridad e inestabilidad por falta de contratos y las condiciones habitacionales especialmente de los inquilinos.

\subsection{Prácticas de apropiación espacial}

¿Cómo funcionaron la apropiación, subdivisión del suelo y la edificación en la Villa 31 tradicionalmente? La Villa no toma en cuenta las normativas y códigos de planeación y crece bajo sus propias reglas. Tradicionalmente el acceso a la vivienda en el barrio se dio por la ocupación (invasión) de un terreno vacante y la inmediata edificación auto gestionada. De esta manera el ocupante se apropia del lugar, como dueño del predio, aunque jurídicamente no tiene un título de propiedad.

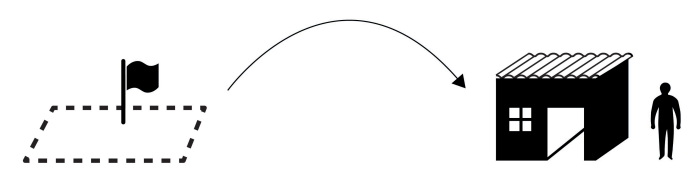

Figura 8: Apropiación del suelo por la ocupación de un terreno y edificación auto gestionada Elaboración propia

"Yo ya vivo en la villa hace muchos años. Cuando llegué aquí, no había ningún mercado de vivienda. En este tiempo las familias mismas ocuparon los terrenos. Después de la ocupación eras dueño del lugar y empezabas a construir tu propia casa. Uno no construyó en donde quería, había personas que eran responsables, o por lo menos se sentía responsable, para asegurar un orden mínimo. Estas personas, te asignaron los terrenos, muchas veces eran terrenos en zonas, donde ya se habían asentado más gente de tu misma región de origen” (Entrevista: Alvina Lugos, 2014 / Dueña de casa y arrendadora Villa 31).

\footnotetext{
${ }^{11}$ Mercado inmobiliario informal: transacciones inmobiliarias mercantilizadas (es decir monetizadas) que no están ajustadas a las normas legales y urbanas, que no se convienen estrictamente a la lógica económica de la comercialización de inmuebles formales y cuyos actores interactúan por fuera de las regularizaciones económicas legales y construyen un entramado diferente al del mercado formal (Cravino 2006: 140).

${ }^{12}$ El mercado informal de vivienda sigue siendo una temática poca investigada, trabajos antecesores son las investigaciones de la antropóloga María Cristina Cravino y de la economista Cecilia Kismer de Olmos.
} 
La práctica de apropiación espacial (ocupación y la subdivisión de los terrenos) en la Villa 31, se orienta desde un principio por los criterios del origen. Eso significa, que la región o el país de origen son determinantes en términos de distribución de suelo y el acceso la vivienda.

El acceso y crecimiento de la vivienda esta principalmente dominado por las condiciones físicas del terreno, los recursos económicos y la necesidad espacial de cada familia, como también las negociaciones entre los habitantes en el barrio. Con el paso del tiempo, se atraen más familias a vivir en la Villa, y el proceso continua. En consecuencia, se pueden observar diferentes formas de subdivisiones de los terrenos y la edificación de las casas en altura.
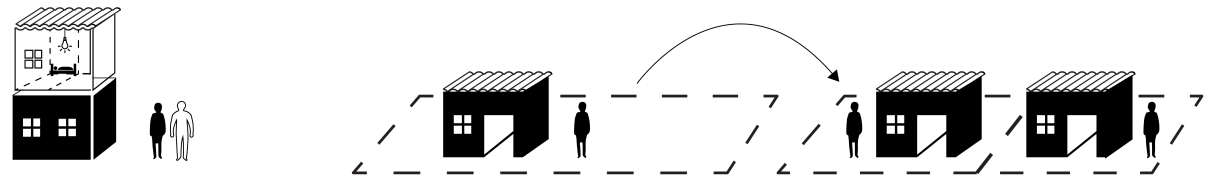

Figura 9: Subdivisión de terrenos / edificación al lado y en altura

Elaboración propia

Durante los años del 1991 al 2001 la población en la Villa 31 creció un $116 \%$, ese crecimiento implicó que se asentaron aproximadamente 1.932 personas por año en el barrio (Censo Nacional de Población, Hogares y Viviendas 2010 en la Ciudad de Buenos Aires). Desde entonces la Villa 31 llega a sus límites, no puede expandirse más en su superficie, así el crecimiento poblacional impulsó la densificación extrema, la cual promovió la edificación en altura y sobre bordes ya consolidados. En este contexto también se limita el acceso a un propio terreno dentro del barrio. ${ }^{13}$

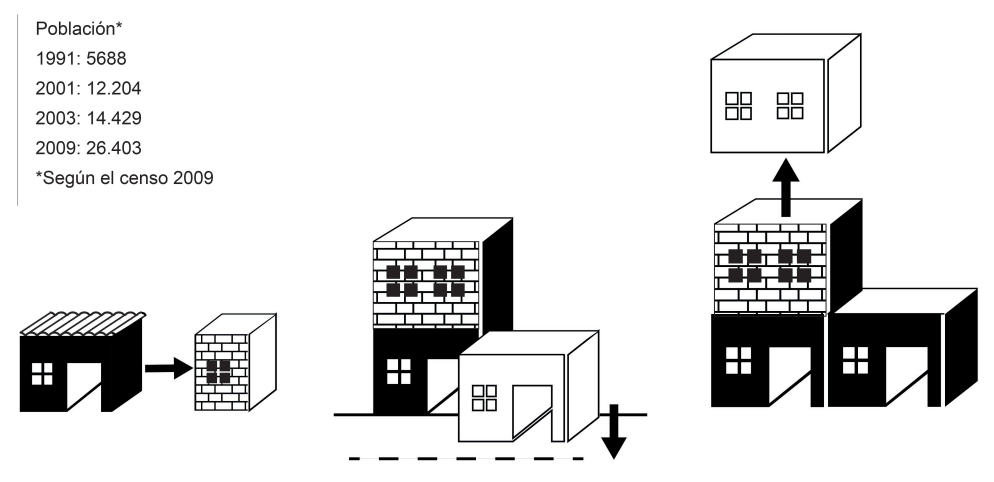

Figura 10: Densificación

Elaboración propia

\subsection{Transformación del acceso a la vivienda por el mercado informal}

¿Cómo se transformó el acceso a la vivienda por el desarrollo del mercado inmobiliario informal? La constante demanda habitacional, en conjunto con la falta de tierras vacantes, provocan la edificación específica con el fin de alquiler. En consecuencia, la vivienda en la Villa adquiere un nuevo costo monetario, el cual no existía antes y aumenta el valor de la propiedad informal.

\footnotetext{
${ }^{13}$ Según la antropóloga Cristina Cravino, el acceso un terreno propio, sin tener que pagar por este, desde los años 1995 es excepcional (Cravino 2006, S.160).
} 


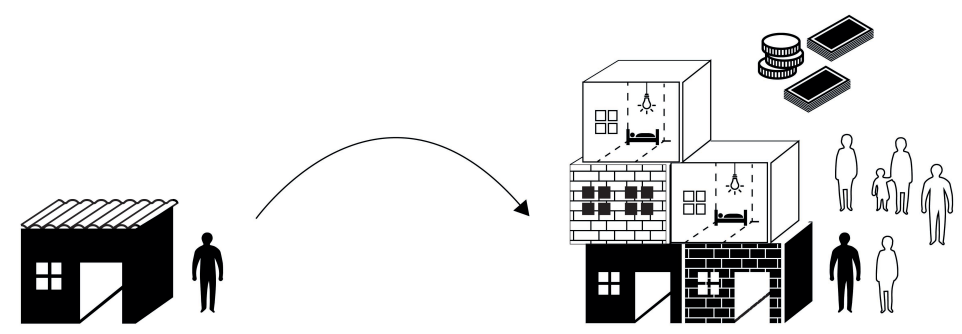

Figura 11: La vivienda para alquiler implica un nuevo costo Elaboración propia

"Con los años, el barrio ha cambiado mucho. Ha llegado más y más gente. Este desarrollo empezó más o menos desde quince años. De repente querían quedarse tanta gente en la villa, que ya no habían suficientes terrenos para todos. Desde entonces la gente empezó a alquilar cuartos y edificar su casa para poder arrendar más cuartos" (Entrevista: Carmen 2014 / Dueña de casa Villa 31).

La comercialización de espacios habitables en la Villa 31, predispone al acceso a la vivienda y cambia los principios de la propiedad informal dentro del barrio. Si antes todos los habitantes de la Villa 31 eran dueños de sus terrenos y casas (aunque jurídicamente no tenían los títulos de propiedad), hoy existen dueños los cuales de repente sub-alquilan a inquilinos que viven de manera temporal o a largo plazo en condiciones de alquiler. En consecuencia al desarrollo del mercado de vivienda, se puede observar el establecimiento de nuevos actores, como también cambios en el sentido de la propiedad informal.

"La categoría del propietario o arrendatario, se define por el hecho de que tienes una casa o no. Si aquí en la Villa figuras como inquilino, es por el hecho de que realmente no tienes nada. Si una persona no tiene acceso a un terreno o una casa en la Villa, allí las cosas se complican realmente. La mayoría de la gente que viene de los países limítrofes o las provincias del norte, no tienen suficiente dinero, automáticamente forma parte de la categoría del inquilino. Esta gente no tiene las redes y ni el dinero para comparase una casa, en estos casos no les queda nadas más que el alquilar" (Entrevista: Milcar Paredes, 2014 / Dueño de casa Villa 31).

\subsection{Funcionamiento del mercado de vivienda en la Villa 31}

¿Cómo funciona el mercado de vivienda?

El mercado de vivienda en la Villa 31 es un sistema local. La participación funciona por el contacto directo, generalmente se trata de contactos previos, porque casi nadie viene sólo a vivir en una Villa desconocida. Las informaciones circulan de boca en boca, o a través de avisos, puestos directamente en los muros de la vecindad. Aunque no figuran inmobiliarias o agentes, existen personas de contacto, que saben quién alquila y bajo qué condiciones, de esta manera se implementa un sistema de recomendación y aseguración. Dado a esta observación, las relaciones y redes sociales juegan un papel importante, y se puede afirmar que la integración en la comunidad es una condición previa para la participación en el mercado de vivienda.

"Yo tengo la impresión que acá en la Villa funciona todo a través de contactos. Si vives en la Villa hace cierto tiempo conoces a tus vecinos, sabes quienes alquilan, en quien puedes confiar, o no y más que todo, ¿cuáles son los precios para que tipo de habitación?” (Entrevista: Griselda González, 2014 / Inquilina Villa 31). 

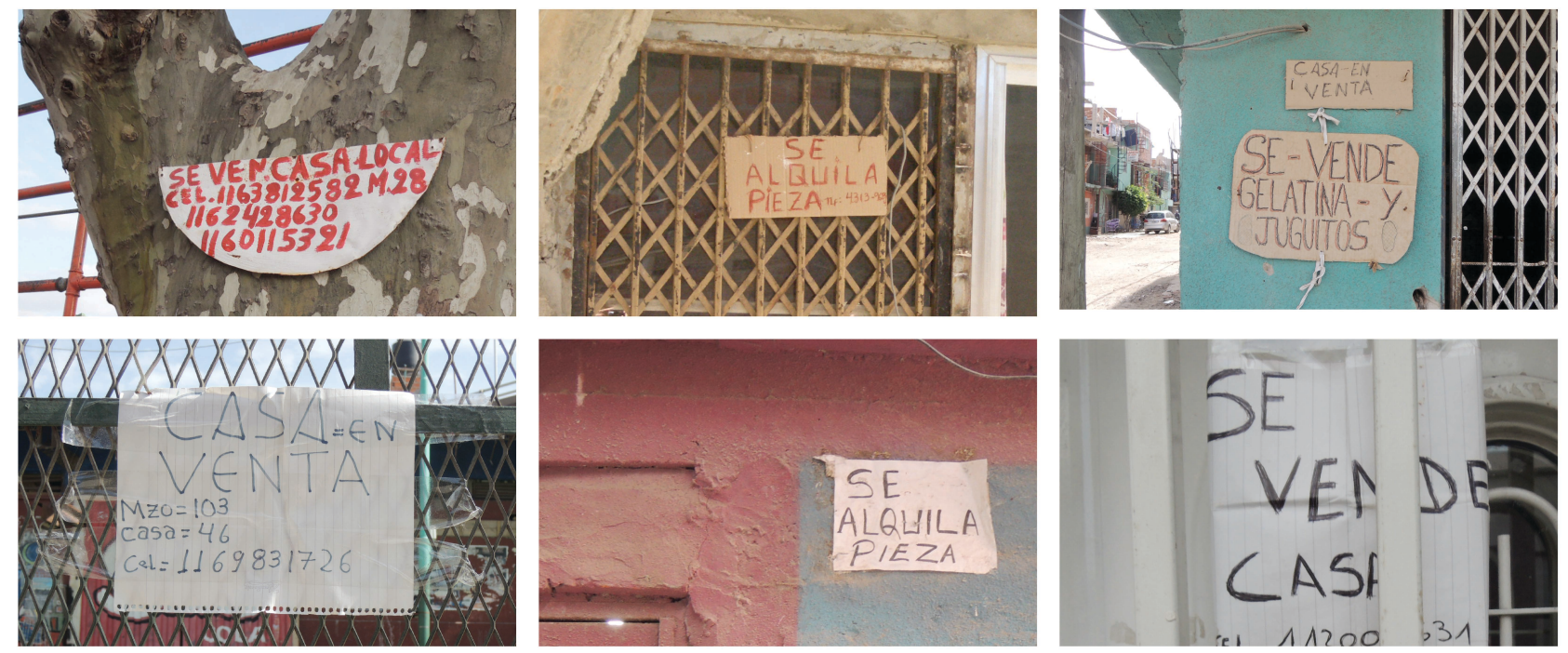

Figura 12: Avisos en el barrio

Propias imágenes fotográficas (2014 / 2015)

Los procesos en el mercado de vivienda avanzan en el transcurso de diversas negociaciones, entre los mismos habitantes del barrio. Existen distintos tipos de actores y tanto los dueños como también los inquilinos persiguen diferentes motivaciones. Hay dueños que solo sub-alquilan un cuarto en su casa, a gente conocida o familiares para obtener una mínima subvención a su ingreso mensual. Otros que edificaron su casa mayoritariamente para el alquiler y alquilan distintos cuartos con un fin de lucro. Sin embargo, las formas del alquiler en un contexto familiar (una casa tradicional) se reducen exponencialmente, y al mismo tiempo se puede observar una profesionalización en el ámbito del subalquiler.

"El alquiler de cuartos y la venta de casas realmente se transformaron en un negocio. La gente edifica sus casas en altura por el simple hecho de hacer plata, no es nada más. No recuerdo muy bien en cuando empezó esto del mercado de vivienda, eso de que la gente ya solo piensa en su ganancia. Aquí en el barrio hay gente que alquila hasta 30 cuartos" (Entrevista: Agustina González 2014 / Dueña de casaVilla 31).

En la actualidad, los recién llegados principalmente dependen de las ofertas del mercado de vivienda. ${ }^{14}$ Según Cravino, el recién llegado "antes comenzaba albergando un tiempo en casa de un pariente, hasta construir en algún lugar libre su propio „ranchito“ y luego la casa de mampostería” (cf. Cravion 2006: 52). Si hubo que pagar algo fueron montos pequeños, por el material o la subdivisión del terreno. Pero con el desarrollo del mercado, la estadía en casa de un pariente suele reducirse a una solución únicamente temporal. Por lo tanto, se puede observar la desvinculación de la vivencia del contexto familiar.

Entre los inquilinos existen los que alquilan temporalmente y luego, si sus condiciones lo permiten y cuenta con mayor capital, buscan comprar una casa en mercado inmobiliario informal. Pero hay otros que alquilan a largo plazo, porque sin obtener las capacidades económicas se extiende la fase del alquiler. Los inquilinos en general suelen mudarse frecuentemente, dado a las precarias condiciones habitacionales y el aumento del alquiler por parte de los dueños de casa.

"Hoy hay gente la cual vive como yo, no solo temporalmente, sino por largas estadías en situaciones de alquiler. De vez en cuándo cambian el lugar, pero siempre son inquilinos. Nadie alquila en la Villa porque le gusta, pero hoy es casi imposible conseguir un terreno y construir tu propia casa" (Entrevista: Aldo Cruz, 2014 / Inquilino Villa 31).

\footnotetext{
${ }^{14}$ Siguiendo la argumentación de Cravion ahora son distintos los escalones del acceso residencial,» La práctica de recibir al pariente recién llegado y co-residir con un allegado u otro núcleo familiar se modificó de tres formas: se acortó el tiempo de albergarlos solidariamente, en muchos caso se optó por alquilar algún espacio residencial a ellos, o se las alienta para que se mudan a un cuarto de alquiler en el mismo barrio al poco tiempo de llegar «(Cravino: $2006: 158)$.
} 

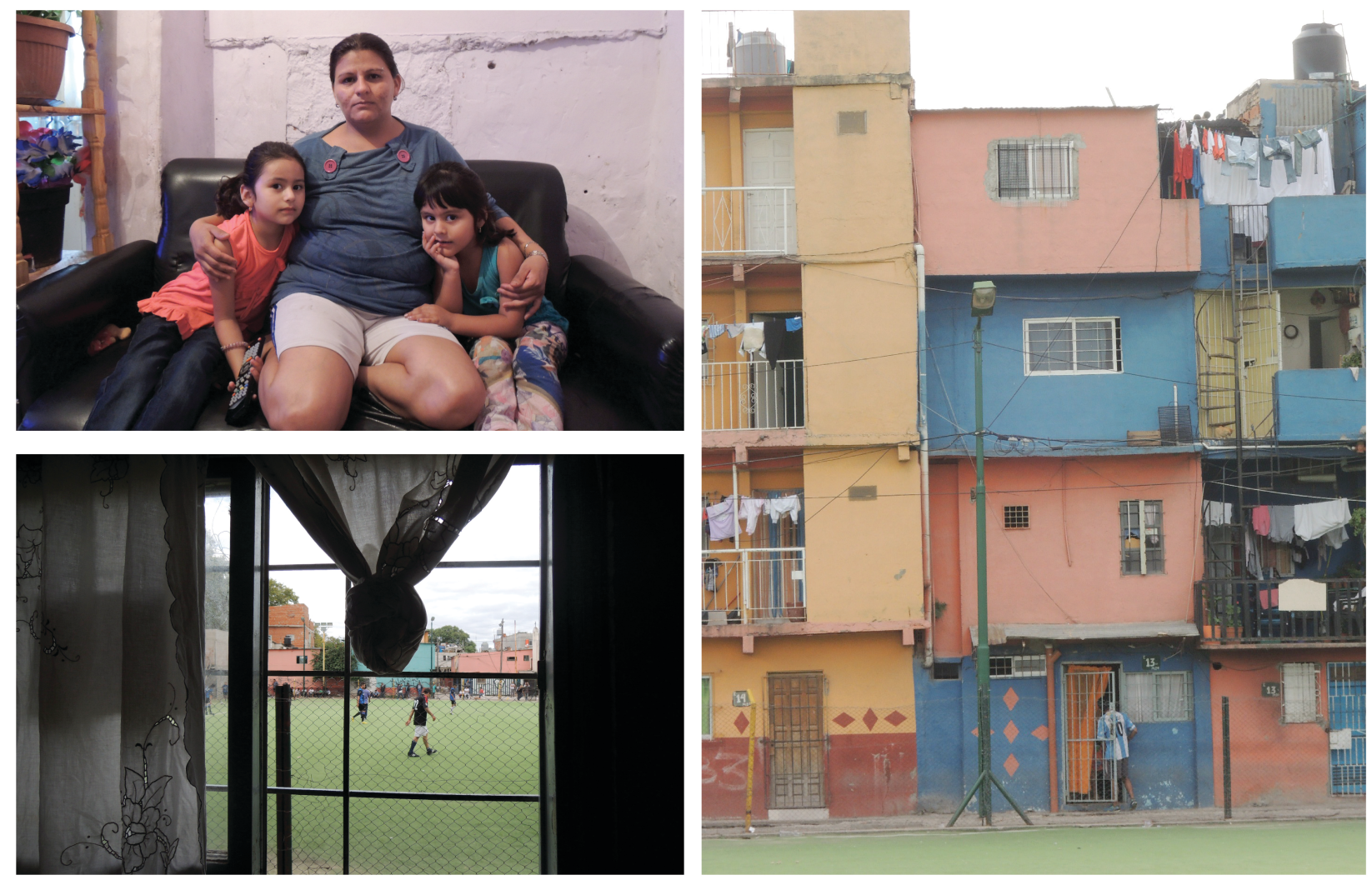

Figura 13: Inquilina Villa 31

Propias imágenes fotográficas (2015)

El hecho de que el mercadeo de vivienda de la Villa 31 se encuentra fuera de la regularización estatal, implica la falta de control en diferentes maneras; Por un lado, no existen contratos legales, por eso, para asegurarse, los dueños en su mayoría piden el alquiler con anticipación. Por otro lado, y al contrario los inquilinos no tienen ninguna forma de seguridad, aparte de la recomendación (por familiares o conocidos) que aumenta con un control dentro de la comunidad. La confianza que se brinda a los habitantes debido a su largo período de residencia en el barrio, su compromiso social (por obtener un puesto de delegado etc.), o por su origen étnico, fortalecen la aceptación y la solidaridad concedida por la comunidad. Hoy en día la confianza más que todo juega un papel importante entre el propietario y el inquilino, que están viviendo en situaciones de arrendamiento desde hace ya cierto tiempo. No obstante, en el sentido en el que se van disminuyendo las relaciones entre el inquilino y el dueño, también la confianza pierde de importancia.

"En el barrio realmente no hay seguridad. Por supuesto la Villa tampoco es un lugar sin leyes, pero tienes que entender los códigos. Por un lado el más fuerte domina, el que se anima, que no toma en cuenta a los demás. Si piensas de esta manera, puedes participar en las ocupas y vender el terreno, construir y alquilar, así puedes hacer un poco de dinero. Por el otro lado no te conviene tener la comunidad en contra de ti. Porque si engañaste a la gente en algún momento nadie más va a confiar en ti y tampoco van a alquilar contigo. Estos chismes circulan muy rápido por el barrio" (Entrevista: Gladis Aguilar, 2014 / Dueña y arrendadora Villa 31).

Las condiciones económicas del mercado de vivienda en su mayoría se instalan sobre redes de relaciones previas, en este contexto la negociación de los precios es una práctica común en el mercado de vivienda de la Villa, esto implica que si el dueño e inquilino se conocen se pueden negociar mejores precios. ${ }^{15}$

"Principalmente tengo mis precios establecidos, para definirlos me oriento en los precios de los de más en el barrio. Pero también pasa que hago excepciones, por ejemplo para gente conocida y amigos de

\footnotetext{
${ }^{15}$ Según una encuesta de Cravino en el año 2006 habían aprox. 55 \% de la gente que negoció el precio de la compra de su vivienda.
} 
familiares. Por supuesto no lo puedo hacer siempre, porque si no, no cumplo con mis gastos" (Entrevista: Marta Villachoque, 2014 / Dueña y arrendadora Villa 31).

No obstante, es el dueño quien define el precio del alquiler y su aumento, por lo tanto, los inquilinos se encuentran en una dependencia extrema.

"Siempre puedas trata de negociar el precio, pero realmente solo tienes una posibilidad si conoces al dueño, y el te alquila un cuarto en su propia casita. Si no conoces el dueño, y esta alquila barrios cuartos, no le va a importa bajarte el precio. Solo le importa que todos los cuartos estén ocupados, y que le paguen. Es diferente, si el dueño solo alquila un cuarto, porque entonces vas a convivir realmente, por eso también le importa quien se queda viviendo en su casa y que es una persona de confianza. Así no solo importa el dinero" (Entrevista: Germán Cañiza, 2014 / Inquilino Villa 31).

Para obtener una mayor aseguración, las negociaciones sobre las condiciones del alquiler o la compra de una casa se realizan con la presencia de testigos. Por lo tanto, el mercado de la vivienda de la Villa 31 está sujeto al control social de la comunidad quien está involucrado en los procesos, y puede tomar posición en casos de conflictos.

\subsection{Transformación de Tipologías}

¿Cómo se transformó la construcción y las tipologías por el desarrollo del mercado inmobiliario informal? El negocio del alquiler dado al desarrollo del mercado de vivienda impulsó la construcción y edificación, en consecuencia, se puede observar una profesionalización en dicho ámbito. Este desarrollo implica la transformación de las tipologías típicas en la Villa, ${ }^{16}$ porque para las nuevas construcciones no sólo se utilizan mejores materiales ya que se construye más alto, sino también porque a la vez se vuelven técnicamente más complejas. Desde entonces la auto construcción (por el mismo usuario) fue paulatinamente reemplazada por construcciones profesionales por medio de contratistas.
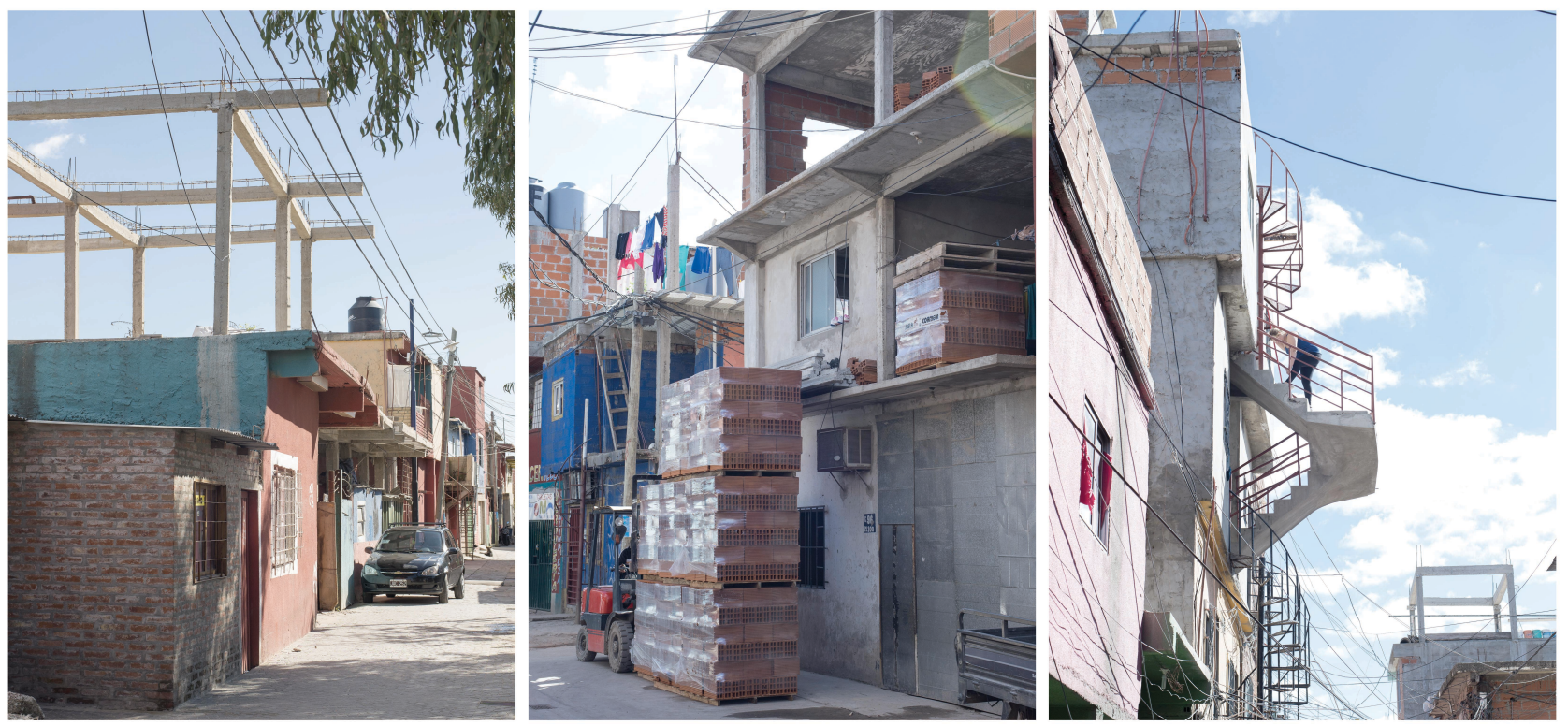

Figura 14: Tipologías desarrolladas en altura Propias imágenes fotográficas (2015)

El desarrollo del mercado de vivienda también implica la transformación de las tipologías típicas en la Villa, a través de la oferta. Generalmente las nuevas tipologías se adaptan de manera flexible a las condiciones espaciales del terreno. Sin embargo, no sólo se están diferenciando las formas de viviendas, sino también las formas de la propiedad informal y del alquiler. Hoy en día no solo se subalquilan cuartos, no obstante también se venden núcleos habitacionales. Como consecuencia se observa que, se disminuyó la superficie disponible para la mayoría de los habitantes y eso aunque se aumento la altura de las edificaciones.

\footnotetext{
${ }^{16}$ Según el Censo 2009 el 46,8 \% de las viviendas eran de solo un piso, el 35,7 \% de dos pisos y el 17,5 \% tenían más de tres pisos.
} 
"Como consecuencia de la falta de tierras aparte del mercado de vivienda se estableció también un mercado de suelo en donde se venden los techos de las casas tradicionales para edificar encima una nueva casa. En este contexto no desapareció el mercado de suelo, sino solo se trasladó verticalmente. "Aquí se vende hasta el techo. En esta parte de la villa hay una demanda tan fuerte por eso ya no existen más terrenos y te ofrecen plata para comprar el techo de tu casa y seguir construyendo" (Entrevista: Augustina González, 2014 / Dueña de casa Villa 31).

\section{CONCLUSIÓN}

Con la consolidación del mercado de vivienda las estructuras actuales y constelaciones de actores en la Villa 31 se han vuelto más complejos. Evidentemente se puede observar una profesionalización en el ámbito económico del mercado. En este contexto el alquiler se rige en su mayoría por la lógica de la ganancia, con la excepción de los que arriendan como estrategia de supervivencia, es decir, para obtener un ingreso mínimo que es destinado a la reproducción de la unidad doméstica, y no a la acumulación. La venta por muchos años se rigió por motivos personales o la emergencia económica (por las cuales la gente abandona la villa y vende su casa). Pero también en este sector se puede observar una profesionalización por los actores que edifican para obtener una ganancia mayor que un subsidio. Nuevos fenómenos que confirmen esta tendencia son la venta por piso (o la unidad habitacional), la venta de techos para seguir construyendo en altura (una nueva casa encima), y la venta de terrenos vacantes después de una ocupación (aunque para dichos terrenos no existen los títulos de propiedad).
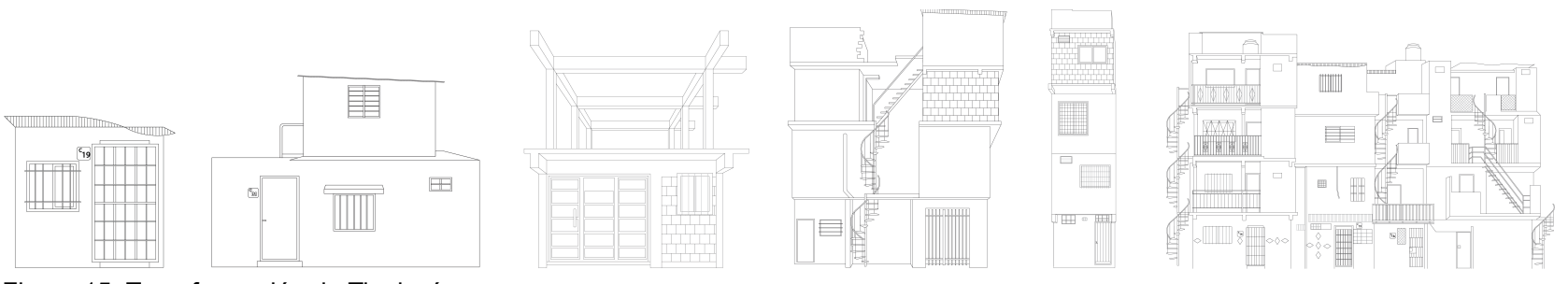

Figura 15: Transformación de Tipologías Elaboración propia (2015)

En particular la problemática de los inquilinos, que no solo alquilan temporalmente sino a largo plazo, obtuvo una nueva dimensión. En este contexto existen actores (inquilinos) que tienen que esta considerados, para proceder a la urbanización reconocida y legal. Queda por aclarar que en los procesos de regularización tradicional, no se ha preguntado a quien corresponden los títulos de propiedad, pero el fenómeno del mercado informal de vivienda (con sus distintos actores) dificultan aún más la "futura urbanización" o la regularización de la Villa 31 (a través de la transferencia de los títulos de propiedad).

Uno de los desafíos al futuro es asegurar la tenencia y la titulación de propiedad, garantizando también la inclusión y permanencia de los inquilinos. En este contexto la planeación tradicional, requiere la implementación de nuevas estrategias e instrumentos, que respondan a los retos de las transformaciones socioeconómicas relacionadas con el desarrollo del mercado informal de la vivienda. 


\section{BIBLIOGRAFÍA}

Cravino, María Cristina (2006): Las Villas de La Ciudad. Mercado e Informalidad Urbana. Universidad Nacional de General Sarmiento. Buenos Aires.

Cravino, María Cristina (2013): Magnitud y crecimiento de las villas y asentamientos en el Área Metropolitana de Buenos Aires en los últimos 25 años. Instituto del Conurbano - Universidad Nacional de General Sarmiento, Buenos Aires.

Dirección General de Estadística y Censos (2009): Censo de Hogares y Población. Villas 31 y 31 bis. Ciudad de Buenos Aires 2009, Buenos Aires. http://estatico.buenosaires.gov.ar/areas/hacienda/sis_estadistico/villa_31_y_31_bis.pdf

Dirección General de Estadística y Censos (2010): Resultados provisionales del Censo Nacional de Población, Hogares y Viviendas 2010 en la Ciudad de Buenos Aires, Buenos Aires. http://www.estadisticaciudad.gob.ar/eyc/wp-content/uploads/2015/07/resultados_provisionales_censo_2010.pdf

Fernández Castro, Javier (2010): Barrio 31 Carlos Mugica. Posibilidades y Limites del Proyecto Urbano en Contextos de Pobreza, Buenos Aires, Instituto de la Espacialidad Humana.

Fernández Edésio 2011: Regularización de asentamientos informales en América Latina. Policy Focus Report, Cambridge, MA, Lincoln Institute of Land Policy.

Foucault, Michael (1967): Andere Räume. En: Barck, Karlheinz (Hg.), 1992: Aisthesis. Wahrnehmung heute oder Perspektiven einer anderen Ästhetik, Leipzig, P. 34 - 46

Glaser, Barney G. / Strauss, Anselm L. 1(998): Grounded Theory. Strategien qualitativer Forschung, Bern, Verlag Hans Huber.

Salerno, Bruno 2014: Neoliberalismo, Políticas Urbanas y Disputa por el Área central de Buenos Aires. El Caso de la Villa de Retiro. In: Janoschka, Michael / Hidalgo Rodrigo (Hg.), 2014: La Ciudad Neoliberal.Gentrificación y exclusión en Santiago de Chile, Buenos Aires, Ciudad de México y Madrid, Madrid, Contested Cities, S. 129 - 149.

Thimmel, Stefan (2004): Villas Miserias in Buenos Aires. Eine Notstandsituation als Dauerzustand Armutsinseln in der Mega City. In: Lanz, Stephan (Hg) (2004): City of COOP. Ersatzökonomien und städtische Bewegungen in Rio de Janeiro und Buenos Aires. metroZones 5. b_books. Berlin

LEY N ${ }^{\circ} 3.343$ (2009): La Legislatura de la Ciudad Autónoma de Buenos Aires.

http://mdut.duot.upc.edu/sites/default/files/L.Bercovich_MDUT\%202010_Anexo\%201.pdf

Programa de mejoras (2010): Gobierno de la Ciudad Autónoma de Buenos Aires 2010, Decreto No 495/ GCABA/10. http://ar.vlex.com/vid/decreto-n-210649699 